\title{
Efficacy Of Silicone Gel In Reducing Scar Formation After Hypospadias Repair: A Randomized Placebo-Controlled Trial
}

This article was published in the following Dove Press journal: Research and Reports in Urology

Mehdi Shirazi'

Ali Akbar Mohammadi ${ }^{2}$

Iman Shamohammadi ${ }^{3}$

Amirhassan Mahboubi ${ }^{4}$

Alireza Makarem (iD) ${ }^{3}$

'Department of Urology, Shiraz University of Medical Science, Shiraz, Iran; ${ }^{2}$ Burn \& Wound Healing Research Center, Division of Plastic \& Reconstruction Surgery, Department of Surgery, Shiraz University of Medical Science, Shiraz, Iran; ${ }^{3}$ Resident of Urology, Shiraz University of Medical Science, Shiraz, Iran; ${ }^{4}$ Professor of Urology, Fellowship in Pediatric Urology, Department of Urology, Tehran Children's Hospital, Tehran, Iran
Correspondence: Iman Shamohammadi Department of Urology, Shiraz University of Medical Science, Shiraz, Iran Email imanshamohammadi@yahoo.com
Background: Hypospadias is one of the most common congenital disorders of the urogenital system that is repaired by surgical method. Literature review shows that silicone gel is effective in preventing and improving hypertrophic scars after surgery. Thus, we conducted this study to evaluate the effect of silicone gel on scar reduction after surgical repair of hypospadias.

Materials and methods: In this randomized double-blind clinical trial, 64 patients who had undergone surgical repair of hypospadias were divided into two groups: 32 patients in the intervention group (silicone gel) and 32 in the control group (placebo). Then, the patients in the silicone gel treatment group were treated twice per day for two months on the site of surgical wound, and the patients in the control group were treated with Vaseline twice per day for two months on the site of surgical wound, too. Scar characteristics (pigmentation, vascularity, pliability, and height) were recorded based on Vancouver's scars scale. Finally, the results of the two treatments on reduction of scars after surgical repair were compared between the two groups. Data were analyzed using SPSS-24.

Results: There were significant differences between the two groups in scar characteristics after surgical repair of hypospadias, such as vascularity, pliability, and height $(\mathrm{P}<0.05)$; however, there was no significant difference in pigmentation $(\mathrm{P}>0.05)$.

Conclusion: The results of this study showed that silicone gel had considerable effects on reduction of scars after surgical repair of hypospadias. However, further studies with larger sample size are recommended to confirm our conclusion.

Keywords: hypospadias, silicone gel, scar

\section{Introduction}

Hypospadias is one of the most common congenital disorders of the urogenital systems. The incidence of hypospadias has been calculated to be one in every 300 male live births. ${ }^{1}$ It is diagnosed immediately after birth by the neonatal clinical examination. Hypospadias has three different types including distal hypospadias, mid-shaft hypospadias, and proximal hypospadias. ${ }^{2}$ The surgical procedure performed to correct hypospadias must provide basic expectations such as proper sexual function, vertical meatus in the middle aspect of the glans, with straight voiding ability and also cosmetic acceptability. ${ }^{3,4}$ The rate of postoperative complications such as fistula, meatal stenosis, and failure to achieve a favorable appearance is high. ${ }^{5,6}$ Choosing an appropriate surgical method that involves an accurate technique along with timely and correct decision after surgery can significantly reduce the complications, leading to higher success rate of the surgery. ${ }^{7,8}$ The wound healing process consists of four phases: Hemostasis, 
Inflammatory, Proliferative, and Remodeling. ${ }^{9,10}$ Practically, hypertrophic scars are kind of abnormal response to healing the wound that occurs due to the increase in the activity of the fibroblasts. ${ }^{11}$ The aim of scars treatment is to prevent distortion in the organ function and create appropriate appearance. ${ }^{12}$ Different treatments to reduce the scars include two major categories; the first category includes medical methods such as Steroids, Silicone, Allantoin, Vitamin A, Vitamin C, and coenzyme Q10, and the second category consists of non-medical methods such as surgical, subcision, microdermabrasion, punch, and laser therapy. ${ }^{13}$ This is the first study on evaluation of the effect of silicone gel on reduction of scars after hypospadias repair. Therefore, we designed this study to ascertain the effect of silicone gel for reduction of scars after surgical repair of hypospadias.

\section{Materials And Methods}

Seventy-four samples among patients who were referred to Nemazi hospital in Shiraz, Iran, for surgical repair of hypospadias by one pediatric urology surgeon (Distal by MAGPI \& Mid by Snodgrass with dartos flap \& proximal by Snodgrass with tunica vaginalis flap methods) were selected and divided into two groups of intervention (recipient of silicone gel) and control (recipient of placebo) using blind randomization. This double-blind randomized clinical trial examination was done after obtaining informed consent from all of the selected patients (Ethics committee reference number: IR.SUMS. MED.REC.1396.53 and IRCTID: IRCT2017080735551N1). Each group included 37 patients. Exclusion criteria were infected wounds, diabetes, collagen vascular disorder, or positive history of skin hypersensitivity to any application. A form containing the demographic data such as age, ethnicity, parental education, socioeconomic status, birth status, and disease information including the type of hypospadias, positive history of previous hypospadias, combined chordee, and surgical technique was prepared first. Then, the patients in the silicone gel treatment group were treated with silicone gel (Cimeosil, Allied biomedical, USA) twice a day for two months on the site of the surgical wound. However, the patients in the control group were treated with petroleum jelly (Vaseline, Unilever, South Africa Ltd) twice a day for two months on the site of surgical wound, too. Treatments were started two weeks after surgical repair. Silicone gel and Vaseline were applied in a thin layer that covered the suture lines of circumcision and longitudinal ventral wound. Packing and tubes of both treatments including Vaseline and silicone gel were similar for both

\begin{tabular}{|c|c|}
\hline 1. PIGMENTATION & 2. VASCULARITY \\
\hline $\begin{array}{l}0=\text { Normal color } \text { (resembles nearby skin) } \\
1=\text { Hypopigmentation } \\
2=\text { Hyperpigmentation }\end{array}$ & $\begin{array}{l}0=\text { Normal } \\
1=\text { Pink } \\
2=\text { Red } \\
3=\text { Purple }\end{array}$ \\
\hline 3. PLIABILITY & 4. HEIGHT (MM) \\
\hline 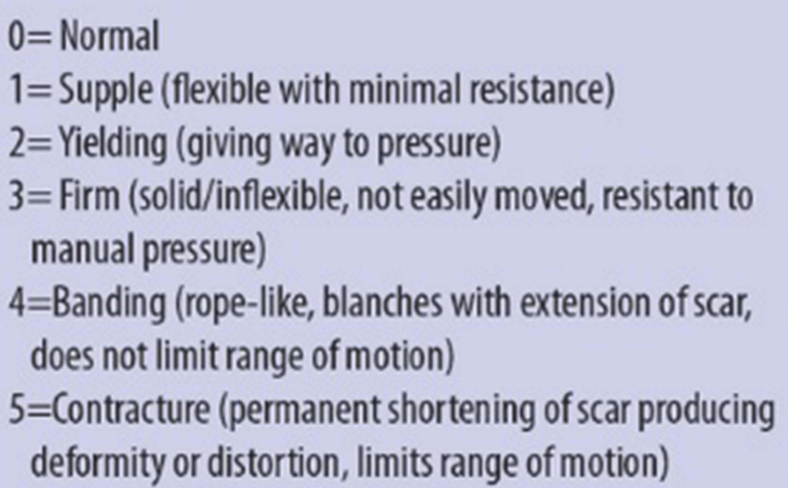 & $\begin{array}{l}0=\text { Normal (flat) } \\
1=<2 \mathrm{~mm} \\
2=>2 \mathrm{~mm} \text { and }<5 \mathrm{~mm} \\
3=>5 \mathrm{~mm}\end{array}$ \\
\hline
\end{tabular}

Figure I Vancouver Scar Scale. 
groups. During the follow-up period, the use of gel application was confirmed by calling the patients' parents. Patients were evaluated 6 months after being completely treated by silicone gel and Vaseline. However, 10 patients were excluded from this study due to poor follow-up. Scar characteristics (pigmentation, vascularity, pliability, and height) were recorded based on Vancouver's scars scale with a plastic surgeon who was not aware of the type of treatment (refer to Figure 1). Finally, the results of the two treatments on reduction of scars after surgical repair were compared between the two groups. Data were analyzed through SPSS-24 using chi-square test. A value of 0.05 was considered significant for all tests.

\section{Ethical Approval}

We declare that our study was approved by the ethics committee of Shiraz University of Medical Sciences, Shiraz, Iran. Additionally, written informed consent was obtained from the patients and we had the permission to publish the case

Table I Distribution And Comparison Of Basic And Clinical Demographic Characteristics Of Patients With Hypospadias Between The Two Groups

\begin{tabular}{|c|c|c|c|}
\hline Characteristics & $\begin{array}{l}\text { Silicone } \\
\text { gel } \\
(n=32)\end{array}$ & $\begin{array}{l}\text { Vaseline } \\
(n=32)\end{array}$ & $P$ value \\
\hline Age, year $(\mu \pm S D)$ & $2.56 \pm 1.04$ & $2.91 \pm 1.44$ & 0.262 \\
\hline $\begin{array}{l}\text { Education Status of Parents, n (\%) } \\
\text { Illiterate } \\
\text { Under Diploma } \\
\text { Diploma } \\
\text { Academic }\end{array}$ & $\begin{array}{l}2(6.3) \\
10(31.3) \\
11(34.4) \\
9(28.1)\end{array}$ & $\begin{array}{l}4(12.5) \\
7(21.9) \\
12(37.5) \\
9(28.1)\end{array}$ & 0.744 \\
\hline $\begin{array}{l}\text { Socioeconomic Status, n (\%) } \\
\text { Poor } \\
\text { Moderate } \\
\text { Good }\end{array}$ & $\begin{array}{l}9(28.1) \\
17(53.1) \\
6(18.8)\end{array}$ & $\begin{array}{l}12(37.5) \\
11(34.4) \\
9(28.1)\end{array}$ & 0.314 \\
\hline $\begin{array}{l}\text { Previous Hypospadias, n (\%) } \\
\text { Yes } \\
\text { No }\end{array}$ & $\begin{array}{l}0(0) \\
32(100)\end{array}$ & $\begin{array}{l}0(0) \\
32(100)\end{array}$ & - \\
\hline $\begin{array}{l}\text { Type of Hypospadias, } n(\%) \\
\text { Distal } \\
\text { Midshaft } \\
\text { Proximal }\end{array}$ & $\begin{array}{l}24(75.0) \\
4(12.0) \\
4(12.0)\end{array}$ & $\begin{array}{l}24(75.0) \\
5(15.6) \\
3(9.4)\end{array}$ & $0.88 I$ \\
\hline $\begin{array}{l}\text { Chordee, n (\%) } \\
\text { Yes } \\
\text { No }\end{array}$ & $\begin{array}{l}9(28.1) \\
23(79.9)\end{array}$ & $\begin{array}{l}7(21.9) \\
25(78.1)\end{array}$ & 0.774 \\
\hline $\begin{array}{l}\text { Surgical Technique, } \mathrm{n}(\%) \\
\text { MAGPI } \\
\text { Snodgrass }\end{array}$ & $\begin{array}{l}25 \text { (78.1) } \\
7(21.9)\end{array}$ & $\begin{array}{l}24(75.0) \\
8(25.0)\end{array}$ & 0.999 \\
\hline
\end{tabular}

Abbreviation: MAGPI, Meatal Advancement and Glanuloplasty Incorporated. details and any accompanying images, the safety of our procedure, and its probable complications. This study was conducted in accordance with the Declaration of Helsinki.

\section{Results}

As described, 64 patients (with a mean age of 2 years and 7 months) having hypospadias were treated with silicone gel and Vaseline. Effects of these two types of treatments on reducing scars after surgical repair were compared. The distribution of basic and clinical demographic characteristics of patients with hypospadias is shown in Table 1. As shown in the table and the results of Student $t$-test, the age range of the two groups was the same. Also, Chi-square test showed that there was no significant difference between the two groups in terms of ethnicity, parental education, socioeconomic status, birth status, type of hypospadias, combined chordee, positive history of previous hypospadias repair, and surgical technique $(\mathrm{P}>0.05)$.

The efficacy of treatments on the scar characteristics after the repair of hypospadias is shown in Table 2. There were significant differences between the two groups in scar characteristics after the repair of hypospadias in terms of vascularity, pliability, and height $(\mathrm{P}<0.05)$; however, there was no

Table 2 Comparison Of Scars After Hypospadias Repair Between The Two Groups

\begin{tabular}{|c|c|c|c|}
\hline Characteristics & $\begin{array}{l}\text { Silicone } \\
\text { Gel } \\
(n=32)\end{array}$ & $\begin{array}{l}\text { Vaseline } \\
(n=32)\end{array}$ & P-Value \\
\hline $\begin{array}{l}\text { Pigmentation, n (\%) } \\
\text { Normal } \\
\text { Hypopigmentation } \\
\text { Hyperpigmentation }\end{array}$ & $\begin{array}{l}22(68.8) \\
10(31.2) \\
0(0)\end{array}$ & $\begin{array}{l}13(40.6) \\
18(56.3) \\
1(3.1)\end{array}$ & 0.061 \\
\hline $\begin{array}{l}\text { Vascularity, n (\%) } \\
\text { Normal } \\
\text { Pink } \\
\text { Red } \\
\text { Purple }\end{array}$ & $\begin{array}{l}28(87.5) \\
4(12.5) \\
0(0) \\
0(0)\end{array}$ & $\begin{array}{l}\text { I5 (46.9) } \\
16(50.0) \\
1(3.1) \\
0(0)\end{array}$ & 0.002 \\
\hline $\begin{array}{l}\text { Pliability, n (\%) } \\
\text { Normal } \\
\text { Supple } \\
\text { Yielding } \\
\text { Firm } \\
\text { Banding } \\
\text { Contracture }\end{array}$ & $\begin{array}{l}2 \mathrm{I}(65.6) \\
\text { II (34.4) } \\
0(0) \\
0(0) \\
0(0) \\
0(0)\end{array}$ & $\begin{array}{l}10(31.3) \\
2 I(65.6) \\
I(3 . I) \\
0(0) \\
0(0) \\
0(0)\end{array}$ & 0.018 \\
\hline $\begin{array}{l}\text { Height, } \mathrm{n}(\%) \\
\text { Flat } \\
<2 \mathrm{~mm} \\
<5 \mathrm{~mm} \\
>5 \mathrm{~mm}\end{array}$ & $\begin{array}{l}20(62.5) \\
I I(34.4) \\
I(3.1) \\
0(0)\end{array}$ & $\begin{array}{l}7(21.9) \\
22(68.8) \\
3(9.4) \\
0(0)\end{array}$ & 0.004 \\
\hline
\end{tabular}


significant difference in pigmentation $(\mathrm{P}>0.05)$. Repair of the scars 6 months after silicone gel application is shown in Figure 2, and Figure 3 shows the repair of scars 6 months after placebo administration. Comparison of vascularity, pigmentation, heights, and pliability after hypospadias repair between the two groups is shown in Diagrams 1, 2, 3, and 4, respectively.

\section{Discussion}

One of the long-term complications of hypospadias repair is an inappropriate appearance that leads to a decrease in selfconfidence of patients. ${ }^{12}$ There are different treatments for reduction of scars such as medical therapy, surgical approaches, and minimally invasive methods. Medical therapy includes the use of Steroids, Silicone, Allantoin, Vitamin A, Vitamin C, and coenzyme Q10. ${ }^{13}$ According

\section{a}

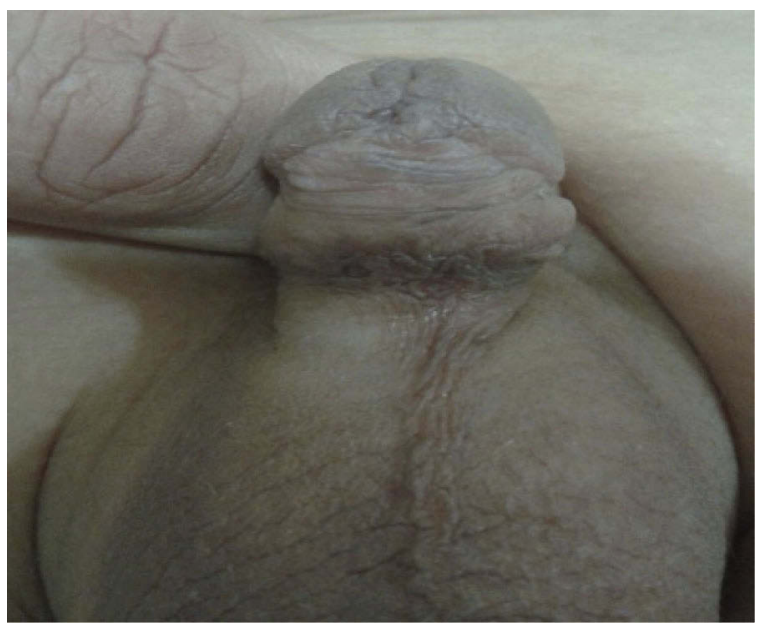

C

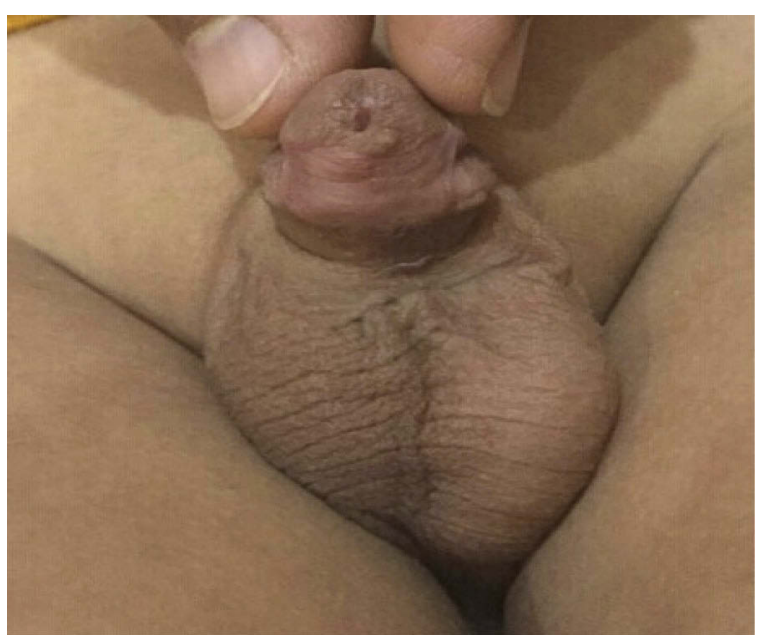

to other interventional studies, more significant effect of silicone gel for reduction of scars compared to other medications is the reason for choosing silicone in our study. ${ }^{14}$ The mechanism of action of silicone products in scar management has not been completely determined. An increase in the skin surface temperature could be involved because the skin surface temperature of hypertrophic scars under silicone is increased, leading to a significant increase in collagenase activity; this could affect scarring. ${ }^{15}$ Also, studies have shown that silicone decreases the evaporation of water from the skin and increases the hydration of the stratum corneum. This process with inhibiting the activity of the mast cells leads to reduced swelling, vasodilation, and formation of additional intracellular background. ${ }^{16}$ Another hypothesis is the static electric field produced by silicone products, which may have an effect on collagen

b

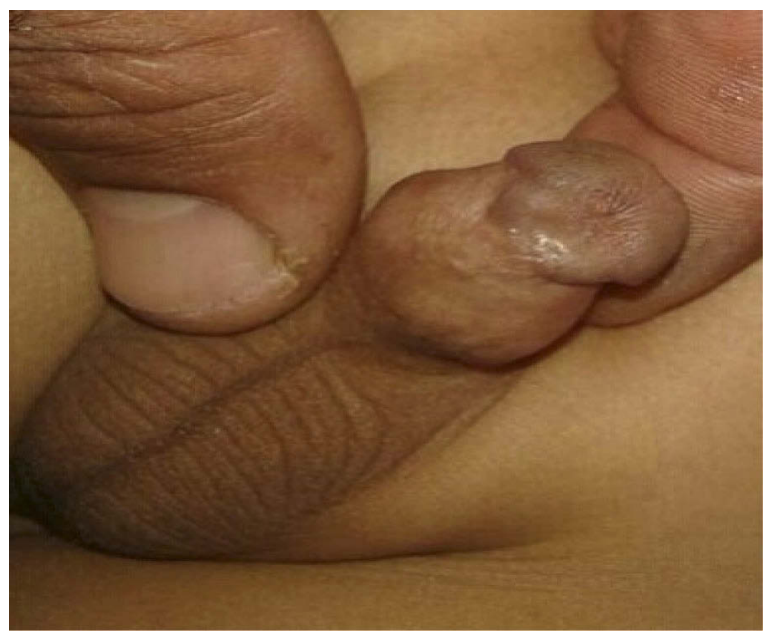

d

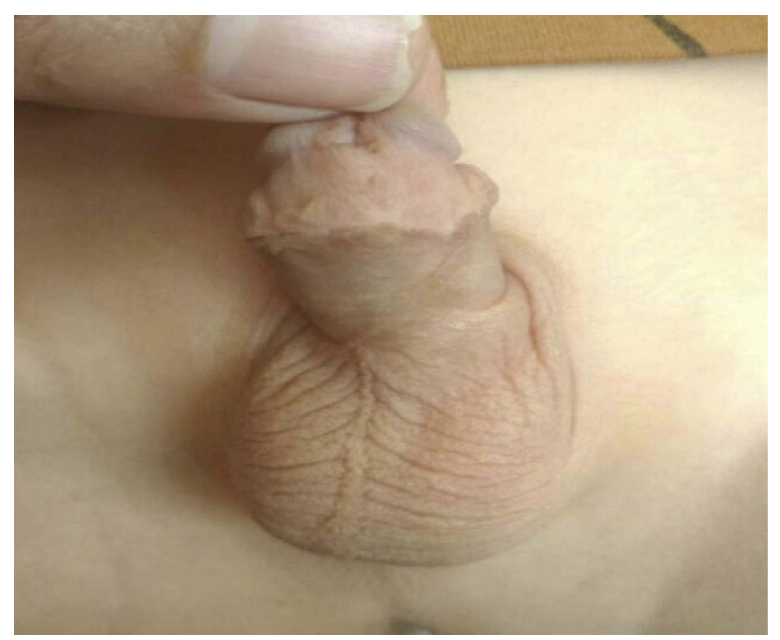

Figure 2 (A) Repair of scars 6 months after silicone gel application. (B) Repair of scars 6 months after silicone gel application. (C) Repair of scars 6 months after silicone gel application. (D) Repair of scars 6 months after silicone gel application. 
a

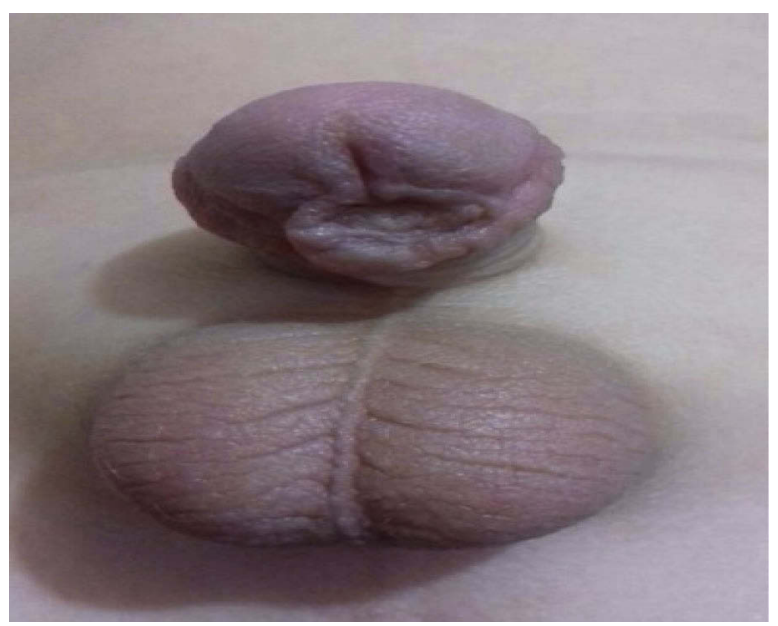

C

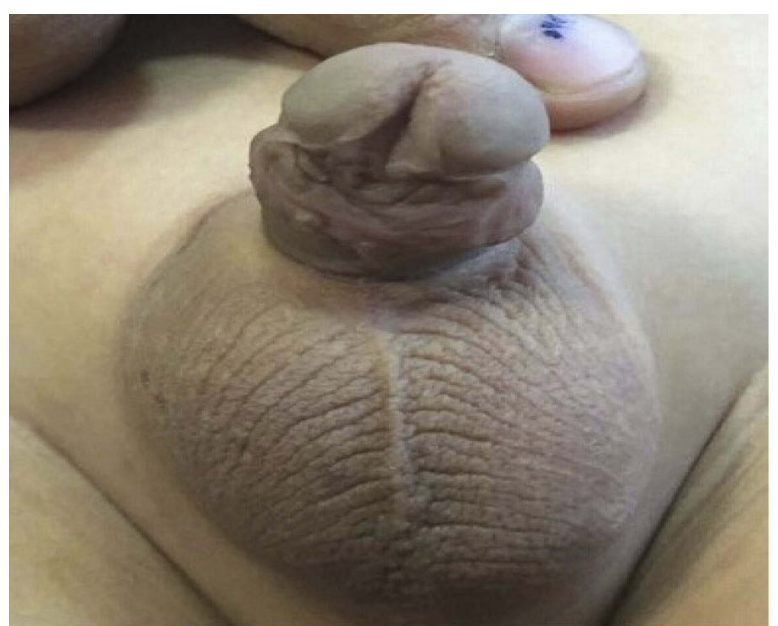

b

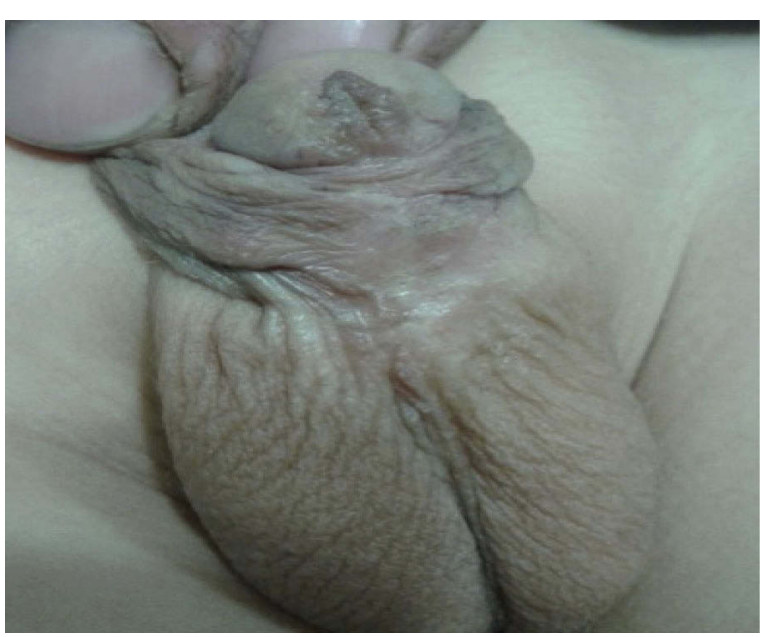

d

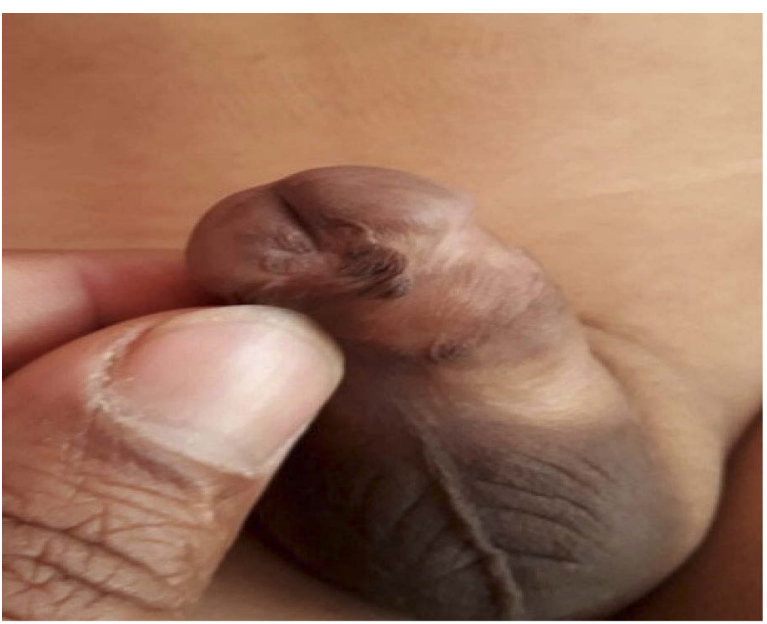

Figure 3 (A) Repair of scars 6 months after placebo administration. (B) Repair of scars 6 months after placebo administration. (C) Repair of scars 6 months after placebo administration. (D) Repair of scars 6 months after placebo administration.

production correction. ${ }^{17}$ In this study, children with hypospadias who undergo a surgical procedure were treated with silicone gel and Vaseline. Results indicated that the silicone gel significantly improved the scar characteristics after surgical repair of hypospadias, such as vascularity, pliability, and height $(\mathrm{P}<0.05)$; however, there was no significant difference in pigmentation $(\mathrm{P}>0.05)$ compared to the Vaseline group. Moreover, demographic and clinical variables such as age, ethnicity, parental education, socioeconomic status, birth status, type of hypospadias, combined chordee, and surgical technique were not associated with the decrease in scars. Other researchers also achieved a variety of results in their studies. For example, Medhi et al (2013) by evaluating the efficacy and safety of an advanced silicone gel formula that prevented post-operative scars showed that height, hyperpigmentation, vascularity, and pliability of post-surgical scars were significantly reduced during the three months of treatment with silicone gel. They concluded that silicone gel was effective and safe in preventing hypertrophic scars and colloid; ${ }^{18}$ this confirms the findings of our study. Kong et al (2014) evaluated the effect of silicone on pain, itching, pigmentation, vascularity, pliability, and height of scars after knee arthroplasty; it was also shown that in the silicone gel group, pigmentation and scar height scores were better than the placebo group, but no significant difference was found between the scores of scar pain and post-operative itching between the two groups. ${ }^{19}$ However, in our study, silicone gel significantly decreased the scars after surgical repair of hypospadias. Wananukul et al (2013) also investigated the effect of onion extract in silicon derivative gel in preventing hypertrophic and colloidal scar in children with scarring of middle sternotomy. 


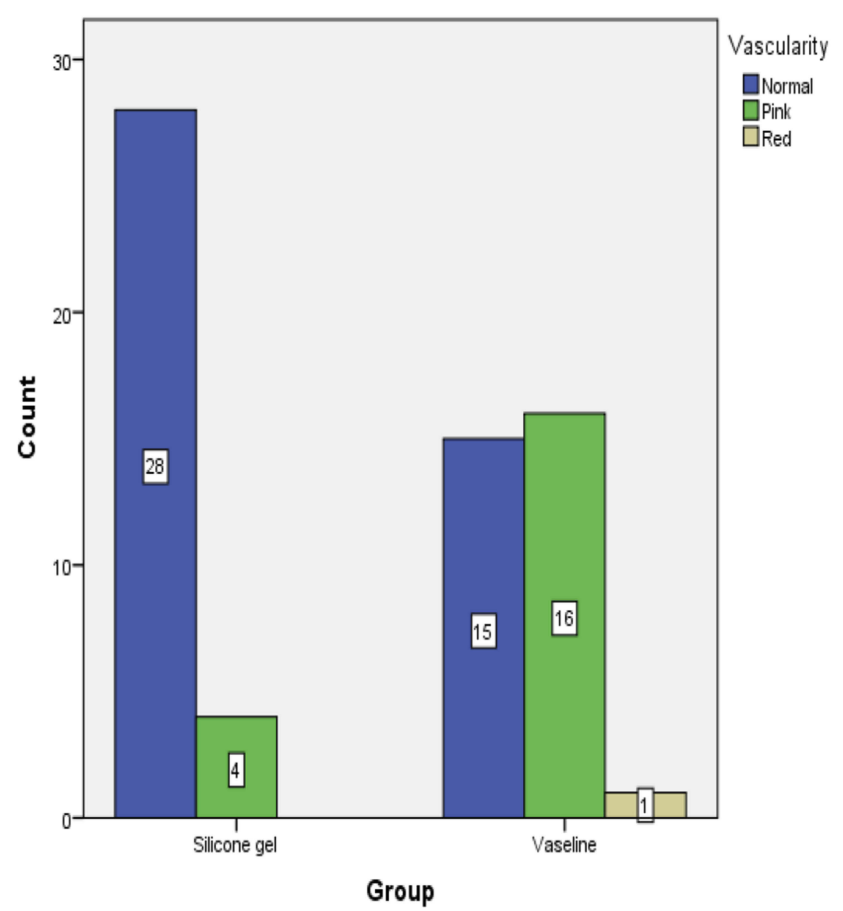

Diagram I Comparison of vascularity after hypospadias repair between the two groups.

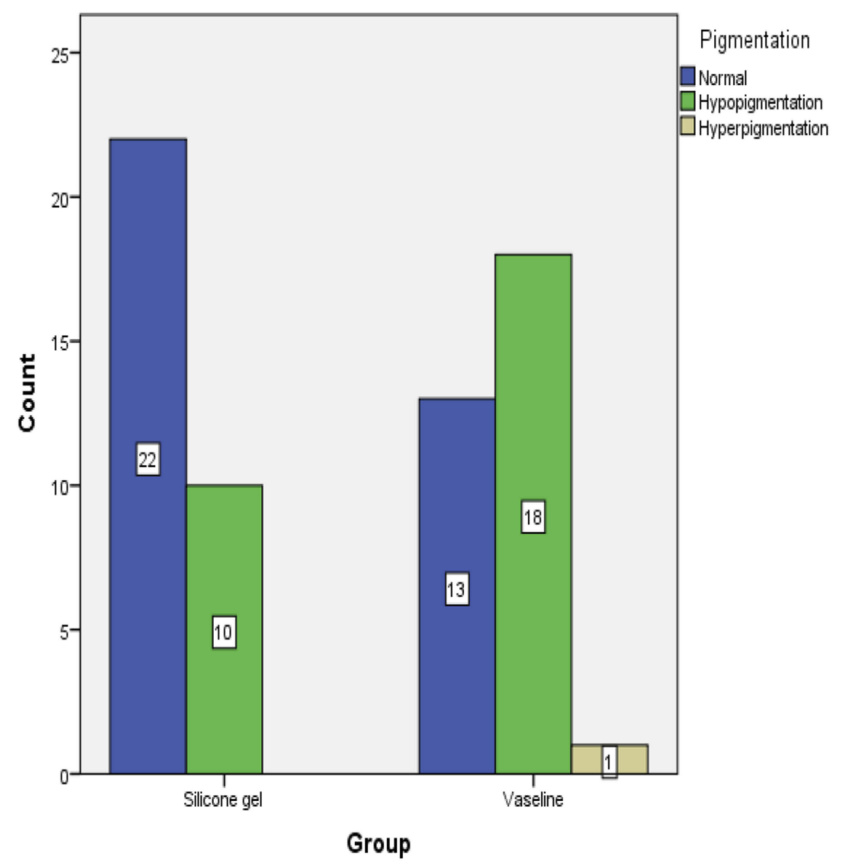

Diagram 2 Comparison of pigmentation after hypospadias repair between the two groups.

Their study showed that $20 \%$ of the patients in the silicone gel group did not have any scars compared to the placebo group (3.3\%). Thus, the silicone gel containing onion extract could significantly decrease the incidence of

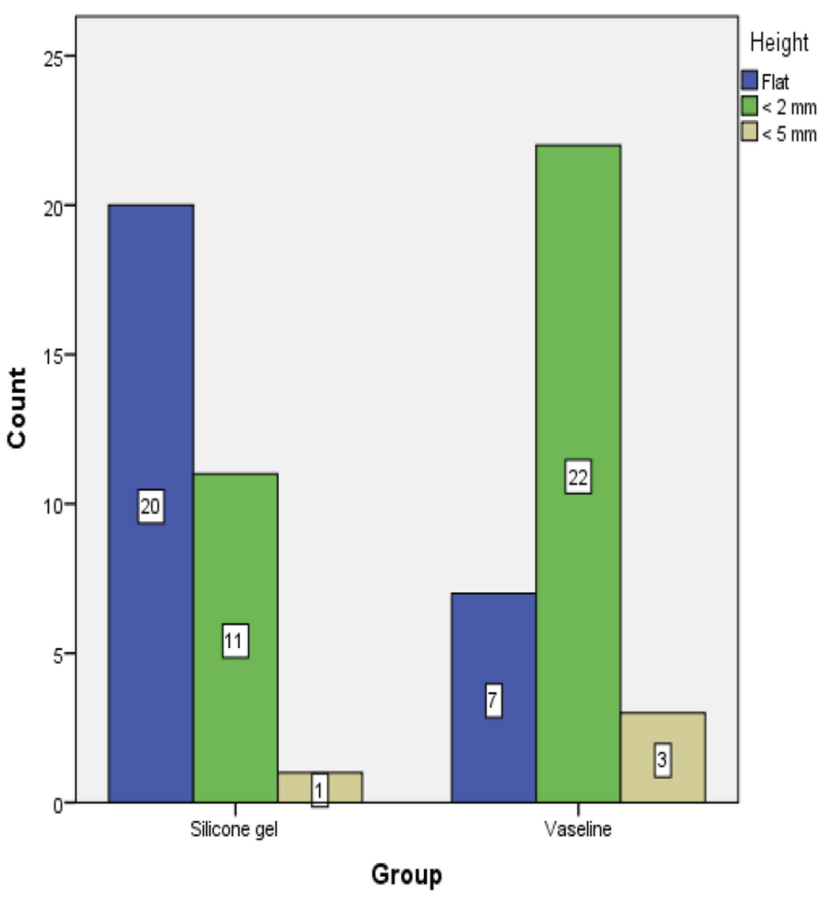

Diagram 3 Comparison of the heights after hypospadias repair between the two groups.

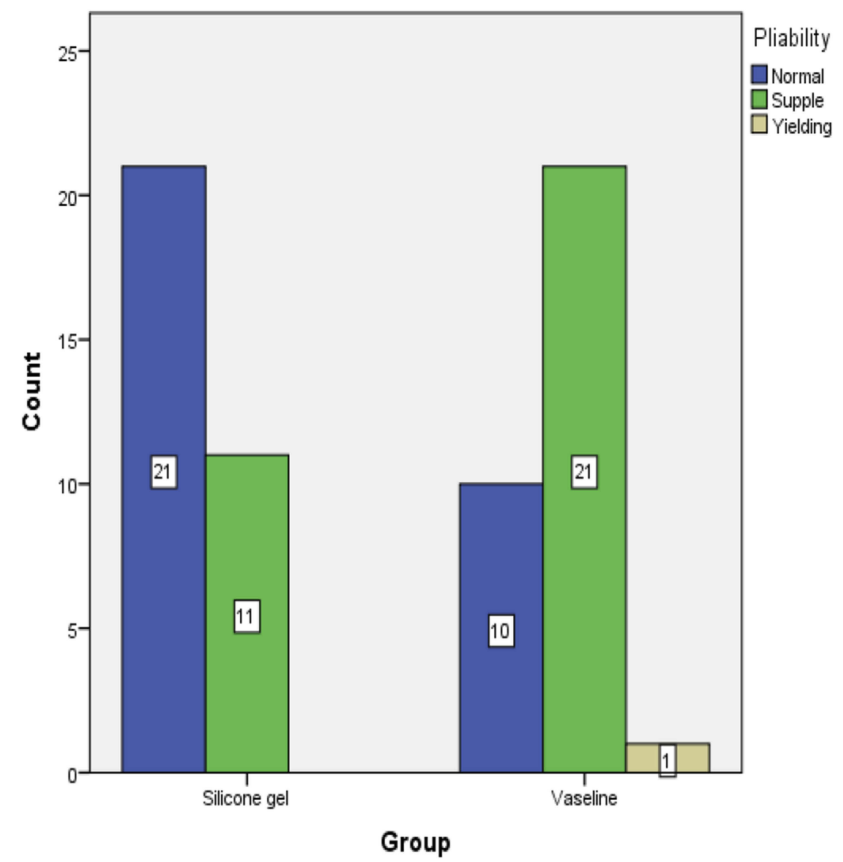

Diagram 4 Comparison of pliability after hypospadias repair between the two groups.

hypertrophic scars after the operation of middle sternotomy in children; however, ${ }^{20}$ this again confirms the findings of our study. It should be noted that many potential factors are involved in the excessive growth of the scar. Excessive 
growth of scar depends on various factors such as anatomical region, patient race, lesion depth, and type of lesion. Finally, the scar is detected by genetic factors, presence of infection and long-term immune responses. In some people, wound repair process leads to exacerbation of response that causes scar formation, which may lead to inappropriate appearance and functional problems. The final result of this process is the formation of additional scars. ${ }^{21}$ In all scars, due to the production of collagen and active metabolism that causes shrinkage of the lesion, the appearance of scar becomes worse during three months. Then, the collagen production process reduces and collagenase begins breaking down the hypertrophic scars; then, it leads to a decrease in the redness of the scars and its softness. This process is a scar evolution. Because of this, in all studies, after a few months, the use of placebo reduces the scar, but this improvement is less than the reduction of scar in patients who have had proper treatment. ${ }^{13,22}$

This study had several limitations. Firstly, the sample size of the middle and proximal hypospadias in the intervention and control groups in this study was low. Secondly, pain and itching were not evaluated in this study. Thirdly, there are no data on their parents' assessment about the appearance of their children's penis.

\section{Conclusion}

Silicone gel had considerable effects on reduction of scars after surgical repair of hypospadias. However, further studies with larger sample size are recommended to confirm our conclusion.

\section{Data Sharing Statement}

Individual participant data will be available. All of the individual participant data collected during the trial, after deidentification, will be shared. Other study-related documents (study protocol, statistical analysis plan, informed consent form, and analytic code) will be made available. The data will be accessible for 3 years after publication.

\section{Acknowledgment}

The authors would like to thank Dr Nasrin Shokrpour for the editorial assistance in the Research Consulting Center (RCC) of Shiraz University of Medical Science and improvement of the use of English in the manuscript.

\section{Disclosure}

The authors declare that they have no conflicts of interest in this work.

\section{References}

1. Baskin LS. Hypospadias and urethral development. J Urol. 2000;163 (3):951-956. doi:10.1016/S0022-5347(05)67861-5

2. Snodgrass W. Hypospadias. In: Wein J, Kavoussi R, Novick A, Partin W, Peters A, editors. CAMPBELL-WALSH Urology. 10th ed. Saunders; 2012:758.

3. Braga LH, Lorenzo AJ, Salle JL. Tubularized incised plate urethroplasty for distal hypospadias: a literature review. Indian $J$ Urol. 2008;24(2):219-225. doi:10.4103/0970-1591.40619

4. Cheng EY, Vemulapalli SN, Kropp BP, et al. Snodgrass hypospadias repair with vascularized dartos flap: the perfect repair for virgin cases of hypospadias? J Urol. 2002;168(4 Pt 2):1723-1726. doi:10.1016/ S0022-5347(05)64398-4

5. Snodgrass W. Tubularized, incised plate urethroplasty for distal hypospadia. J Uro. 1994;2(1):20-151.

6. Hoag CC, Gotto GT, Morrison KB, Coleman GU, Macneily AE. Long-term functional outcome and satisfaction of patients with hypospadias repaired in childhood. Can Urol Assoc J. 2008;2:2331. doi: $10.5489 /$ cuaj. 521

7. Jones BC, O'Brien M, Chase J, Southwell BR, Hutson JM. Early hypospadias surgery may lead to a better long-term psychosexual outcome. $J$ Urol. 2009;182(1):1744-1749. doi:10.1016/j. juro.2009.02.089

8. Asklund C, Jensen TK, Main KM, Sobotka T, Skakkebaek NE, Jørgensen N. Semen quality, reproductive hormones and fertility of men operated for hypospadias. Int $J$ Androl. 2010;33(1):80-87. doi:10.1111/j.1365-2605.2009.00957.x

9. Velnar T, Bailey T, Smrkolj V. The wound healing process: an overview of the cellular and molecular mechanisms. J Int Med Res. 2009;37(5):1528-1542. doi:10.1177/147323000903700531

10. Doillon CJ, Dunn MG, Bender E, Silver FH. Collagen fiber formation in repair tissue: development of strength and toughness. Coll Relat Res. 1985;5(6):481-492. doi:10.1016/S0174-173X(85)80002-9

11. Alster TS, West TB. Treatment of scars: a review. Ann Plast Surg. 1997;39(1):418-465. doi:10.1097/00000637-199710000-00014

12. Perkins K, Davy RB, Wallis KA. Silicone gel: a new treatment for burn scars and contractures. Burn. 1982;9(2):201-204. doi:10.1016/ 0305-4179(83)90039-6

13. Mustoe TA, Cooter RD, Gold MH. International clinical recommendations on scar management. Plast Reaconstr Sur. 2002;110(4):560571. doi:10.1097/00006534-200208000-00031

14. Ahn ST, Monafo WW, Mustoe TA. Topical silicone gel for the prevention and treatment of hypertrophic scar. Arch Surg. 1991;126 (4):499-504. doi:10.1001/archsurg.1991.01410280103016

15. Borgognoni L. Biological effects of silicone gel sheeting. Wound Repair Regen. 2002;10(3):4-118. doi:10.1046/j.1524-475X.2002. 00205.X

16. Chan KY, Lau CL, Adeeb SM, Somasundaram S, Nasir-Zahari M. A randomized, placebo controlled, double blind, prospective clinical trial of silicone gel in prevention of hypertrophic scar development in median sternotomy wound. Plast Reconstr Surg. 2005;116 (1):1013-1020. doi:10.1097/01.prs.0000178397.05852.ce

17. Hirshowitz B, Lindenbaum E, Har-Shai Y, et al. Static electric field induction by a silicone cushion for the treatment of hypertrophic and keloid scars. Plast Reconstr Surg. 1998;101(3):1173-1183. doi:10.1097/00006534-199804010-00001

18. Medhi B, Sewal RK, Kaman L, Kadhe G, Mane A. Efficacy and safety of an advanced formula silicone gel for prevention of postoperative scars. Dermatol Ther (Heidelb). 2013;3(2):157-167. doi:10.1007/s13555-013-0036-8

19. Kong CG, Kim GH, Kim DW, In Y. The effect of topical scar treatment on postoperative scar pain and pruritus after total knee arthroplasty. Arch Orthop Trauma Surg. 2014;134(4):555-559. doi:10.1007/s00402-014-1942-7 
20. Wananukul S, Chatpreodprai S, Peongsujarit D, Lertsapcharoen. A prospective placebo-controlled study on the efficacy of onion extract in silicone derivative gel for the prevention of hypertrophic scar and keloid in median sternotomy wound in pediatric patients. $J$ Med Assoc Thai. 2013;96(11):1428-1433.

21. Nikonen MM, Pitkanen JM, Al-Qattan MM. Problems associated with the use of silicone gel sheeting for hypertrophic scars in the hot climate of Saudia Arabia. Burns. 2001;27(1):30-498. doi:10.1016/S0305-4179(01)00004-3
22. O'sullivan ST, Oshaughnessy M, O'Connor TP. Etiology and management of hypertrophic scars and keloid. Ann R Coll Surg Engl. 1996;78(2):168-175.

\section{Publish your work in this journal}

Research and Reports in Urology is an international, peer-reviewed, open access journal publishing original research, reports, editorials, reviews and commentaries on all aspects of adult and pediatric urology in the clinic and laboratory including the following topics: Pathology, pathophysiology of urological disease; Investigation and

Submit your manuscript here: https://www.dovepress.com/research-and-reports-in-urology-journal treatment of urological disease; Pharmacology of drugs used for the treatment of urological disease. The manuscript management system is completely online and includes a very quick and fair peer-review system, which is all easy to use. Visit http://www.dovepress.com/ testimonials.php to read real quotes from published authors. 